\title{
Spirocerca lupi en perros de Yucatán, México: Reporte de caso y estudio retrospectivo
}

\author{
Roger Rodríguez-Vivas ${ }^{1 *} \otimes\left(\mathbb{D}\right.$ Ph.D; Leonardo Guillermo Cordero ${ }^{\otimes(\mathbb{D})}$ M.Sc; \\ Iris Trinidad-Martínez ${ }^{1} \otimes\left(\right.$ id QFB; Melina Ojeda-Chi ${ }^{1} \otimes(\mathbb{D}$ M.Sc.
}

1 Universidad Autónoma de Yucatán, Facultad de Medicina Veterinaria y Zootecnia, Campus de Ciencias Biológicas y Agropecuarias. Km.
15.5 Carretera Mérida-Xmatkuil, CP 97100. Mérida, Yucatán, México. ${ }^{*}$ Correspondencia: rvivas@correo.uady.mx.

Received: May 2018; Accepted: September 2018; Published: March 2019.

\section{RESUMEN}

Objetivo. Se describe el caso de un perro parasitado con Spirocera lupi en Yucatán, México, y además, se reportan los casos registrados en dos laboratorios durante 18 años de estudios parasitológicos y de necropsias (2000-2017). Materiales y métodos. Para el primer caso, se incluyen hallazgos de necropsia, histológicos y parasitológicos. Para los estudios retrospectivos se realizaron necropsias y estudios coprológicos de Flotación Centrifugada y de McMaster. Resultados. En el paciente del estudio de caso, durante la necropsia se observaron tres nódulos esofágicos que al realizar la incisión de los mismos, se visualizaron nematodos que correspondieron a S. lupi. En el estudio histológico se observó un granuloma eosinofílico que en su interior contenía el nematodo rodeado por un infiltrado inflamatorio moderado que estaba constituido por neutrófilos, eosinófilos, linfocitos, células plasmáticas y macrófagos; delimitado por una cápsula de tejido conectivo fibroso. En el estudio retrospectivo se encontraron prevalencias de 0.18 y $0.48 \%$ mediante pruebas coprológicas y estudios de necropsias, respectivamente. Conclusiones. Spirocerca lupi se encuentra presente en perros de Yucatán, México. Por lo tanto, sería importante considerar esta patología para el diagnóstico diferencial de problemas esofágicos y respiratorios en caninos.

Palabras clave: Estudio coprológico, granuloma eosinofílico, necropsia, perro (Fuente: CAB, MeSH).

\begin{abstract}
Objective. To describe the case report of a parasitized dog with Spirocera lupi in Yucatan, Mexico, as well as report cases registered in two laboratories during 18 years of parasitological and necropsy studies (2000-2017). Materials and methods. A case study is reported, with necropsy, histological and parasitological findings. Likewise, a retrospective study of cases reported in two laboratories where necropsies and faecal Flotation techniques (centrifugal and McMaster) were performed. Results. At the necropsy of the dog, three esophageal nodules were observed, which showed nematodes of S. lupi during the incision of the mass. The histological study showed an eosinophilic granuloma that contained the nematodes at its center, surrounded by a moderate inflammatory infiltrate formed by neutrophils, eosinophils, lymphocytes, plasma cells and macrophages, delimited by a capsule of fibrous connective tissue. In the retrospective study, prevalence of 0.18 and $0.48 \%$ were found by coprological tests and necropsy study, respectively. Conclusions. Spirocerca lupi is present in dogs from Yucatan, Mexico with low prevalence, producing in the esophagus of dogs lesions characterized by eosinophilic granulomas. The need to include this pathology in the differential diagnosis of esophageal and respiratory problems in dogs is disclosed.
\end{abstract}

Keywords: Coprological study, dog, eosinophilic granuloma, necropsy (Source: CAB, MeSH).

Como citar (Vancouver).

Rodríguez-Vivas R, Cordero LG, Trinidad-Martínez I, Ojeda-Chi M. Spirocerca lupi en perros de Yucatán, México: Reporte de caso y estudio retrospectivo. Rev MVZ Cordoba. 2019; 24(1):7145-7150. DOI: https://doi.org/10.21897/rmvz.1602

(C)EI (los) autor (es), Revista MVZ Córdoba 2019. Este artículo se distribuye bajo los términos de la licencia internacional Creative Commons Attribution 4.0 (https://creativecommons.org/licenses/by-sa/4.0/), que permite el uso sin restricciones, la distribución y la reproducción en cualquier medio, siempre que se otorgue el crédito apropiado al autor o autores originales y la fuente. 


\section{INTRODUCCIÓN}

La spirocercosis es una enfermedad causada por el nematodo Spirocerca lupi (Rudolphi 1809). El perro se infecta a través del consumo de escarabajos, aves o pequeños reptiles. La larva migratoria causa hemorragia, estenosis aórtica, endarteritis, aneurisma o ruptura de la aorta. Los signos clínicos de la infección se manifiestan con regurgitación, vómito, tos, disnea, pérdida de peso y muerte súbita por el daño a la aorta. Los nematodos adultos forman nódulos principalmente en el esófago, pero ocasionalmente se pueden presentar en la pared del estómago (1).

Debido a la migración de larvas se pueden formar nódulos o granulomas en otras regiones tales como en órganos torácicos, tracto intestinal, órganos urinarios y en el tejido conectivo de la piel (2). A partir de los granulomas se puede desarrollar sarcomas ( $\underline{3})$.

La spirocercosis se diagnostica con base en la historia y signos clínicos, diagnóstico coproparasitoscópico y molecular, imagen torácica, esofagoscopía y necropsia $(\underline{4}, \underline{5})$.

La spirocercosis causada por S. lupi, ocurre principalmente en caninos, y es predominante en áreas tropicales y subtropicales. La mayoría de los casos son reportados en Israel, Italia, Grecia, Turquía, India, Pakistán, Kenia y Sudáfrica $(\underline{6}, \underline{7})$. En el continente americano se ha reportado en Estados Unidos, Brasil y México $(\underline{8}, \underline{9})$.

En Querétaro, México, S. Iupi ha sido reportada en perros con prevalencia de $4.5 \%$ (9) $)$. En Yucatán, México, Quiñones-Avila et al ( $\underline{10})$ fueron los primeros en reportar la presencia de dos perros con S. Iupi en la necropsia de 38 perros (prevalencia de 5.3\%) y pusieron de manifiesto la importancia de esta parasitosis en perros del estado de Yucatán. Desde este hallazgo, en Yucatán no se ha reportado casos de este nematodo en perros, por tal motivo el presente estudio tiene como objetivo describir el reporte de un caso patológico de un perro parasitado con S. Iupi en Yucatán, así como reportar los casos registrados en dos laboratorios durante 18 años de estudios parasitológicos y de necropsias (2000-2017).

\section{MATERIALES Y MÉTODOS}

Antecedentes. El reporte corresponde a un estudio de caso, con hallazgo de necropsia, histológico y parasitológico. Así como el estudio retrospectivo de casos reportados en los laboratorios de Patología y Parasitología Veterinaria del Campus de Ciencias Biológicas y Agropecuarias de la Universidad Autónoma de Yucatán (CCBA-UADY).

Para el estudio de caso, se recibió un perro de raza criolla de 12 años de edad para estudio de necropsia que presentó antecedentes de regurgitación, vómito y pérdida de peso. El perro nació en Mérida, Yucatán México y nunca salió del estado de Yucatán. El estado de Yucatán se ubica a una latitud de $19^{\circ} 31^{\prime}-21^{\circ} 38^{\prime} \mathrm{N}$ y una longitud de $87^{\circ} 22^{\prime}$ - $90^{\circ} 25^{\prime}$ O; presenta un clima tropical subhúmedo con lluvias en verano. La temperatura ambiente máxima varía de 35 a $40^{\circ} \mathrm{C}$ y la mínima de 10 a $16^{\circ} \mathrm{C}$, con temperatura ambiente promedio de $27^{\circ} \mathrm{C}$. La humedad relativa varía de 65 a $90 \%$, con promedio de $80 \%$ y precipitación pluvial anual de 1,000 $\mathrm{mm}$. Se presentan dos estaciones anuales: lluvia (de junio a noviembre) y seca (de diciembre a mayo) (11).

Diagnóstico del nematodo y prueba histopatológica. En la necropsia del perro se observaron tres nódulos en el esófago que fueron incididos con ayuda de un filo de bisturí para permitir la exposición de los parásitos. Los nematodos parásitos fueron recuperados vivos y contados e identificados con la ayuda de un microscopio estereoscopio. Los nematodos colectados fueron mantenidos en etanol al 95\% (12) y se identificaron de acuerdo a Bowman et al (13).

Adicionalmente se colectaron muestras de las lesiones nodulares en el esófago, las cuales se colectaron en un frasco de plástico de boca ancha con formalina amortiguada al $10 \%$ y buferada a un $\mathrm{pH} 7.2$, manteniendo la relación muestra fijador de $1: 10$, se identificó el frasco y se guardó por 24 h para su fijación.

La muestra fue procesada mediante la técnica de inclusión en parafina y tinción con Hematoxilina-Eosina. Para ello, la muestra se deshidrató con diferentes soluciones consecutivas de alcohol etílico. Después se clarificaron con xilol y se impregnaron en parafina hasta enfriar. Una vez solidificada la parafina y formado el cubo se hicieron cortes seriados de $5 \mu \mathrm{m}$ de espesor, se tiñeron con Hematoxilina-Eosina y se montaron con resina sintética. Finalmente se procedió a la revisión de la muestra con ayuda de un microscopio óptico (14).

Estudio retrospectivo. Para conocer la existencia de casos de S. Iupi en perros en el sureste de México, se revisaron los archivos de los laboratorios de Parasitología y Patología Veterinaria del CCBA-UADY de enero de 2000 a diciembre de 2017. Asimismo se obtuvo información adicional de los casos positivos tales como la procedencia de los animales, edad, raza y la eliminación de huevos por gramo de heces.

Durante el período del estudio retrospectivo se realizaron 1.631 análisis coprológicos de muestras de heces de perros mediante las técnicas de Flotación Centrifugada y McMaster (12). Los huevos de los nematodos fueron identificados usando las descripciones morfológicas y tamaños descritas por Bowman et al (13). Asimismo, en este período se realizaron 835 necropsias de perros de acuerdo a la metodología descrita por Schueneman y Constantino (15).

\section{RESULTADOS}

Durante la necropsia del perro se observaron tres nódulos en el esófago (Figura 1), que durante la incisión de las masas nodulares se visualizaron nematodos adultos de color rojizo (Figura 2). Las lesiones macroscópicas se ubicaban en último tercio del esófago donde cada nódulo presentaban adherencia a la pared del esófago, con un creciendo hacia su lumen ocasionando estenosis. En una región esofágica adyacente a un nódulo se encontró dilatación sacular. Los nódulos tenían medidas que iban entre 4 y $3.5 \mathrm{~cm}$ de largo, 2.5 y $3 \mathrm{~cm}$ de ancho y 2 y $3 \mathrm{~cm}$ de alto; de consistencia firme a dura, donde al corte se encontraba una gran cavidad central, repleta de parásitos nematodos unos de color rojizo y otros blanquecinos, rodeados por detritus celulares y delimitados por una cápsula de tejido conectivo fibroso que en ocasiones se presentaba calcificada; en los tres nódulos se encontró una fistula que abría hacia el lumen del esófago. 

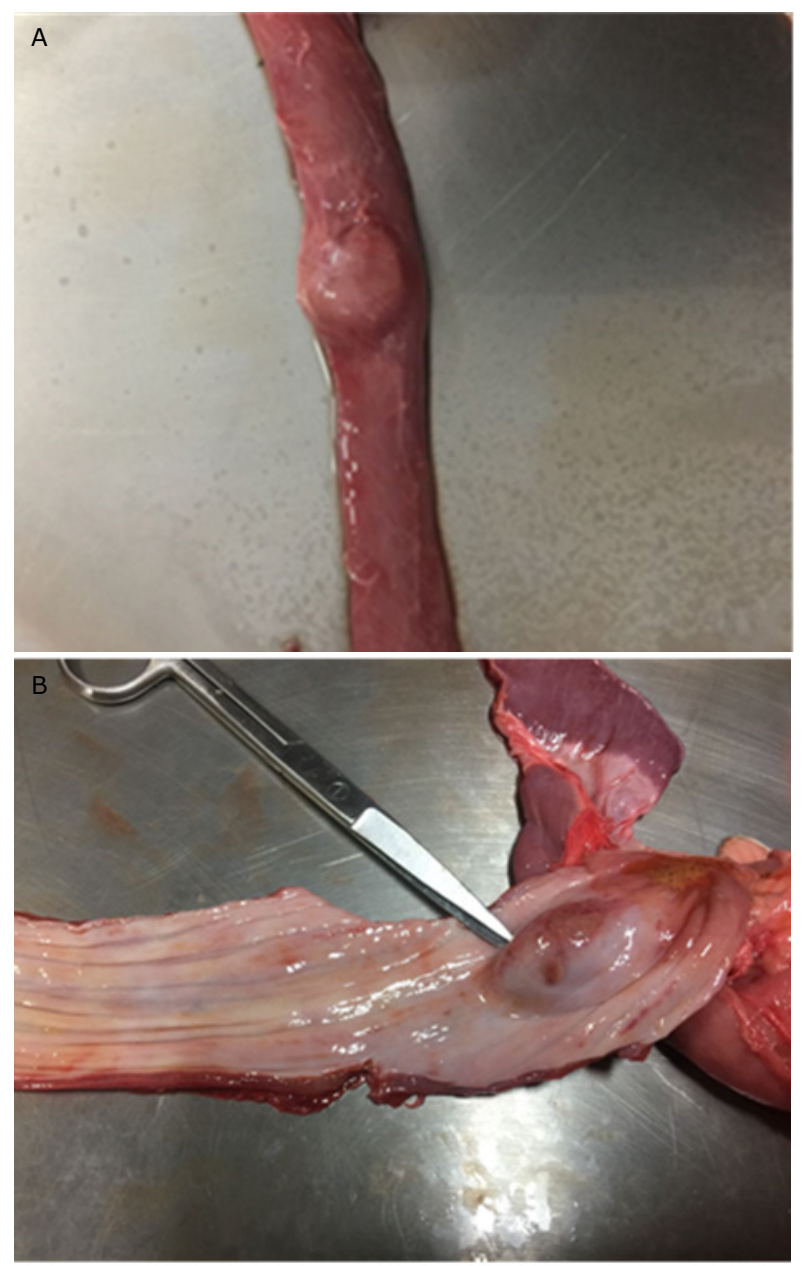

Figura 1. Esófago del paciente canino. (A: vista externa, B: Vista interna) con presencia de un nódulo en la necropsia.
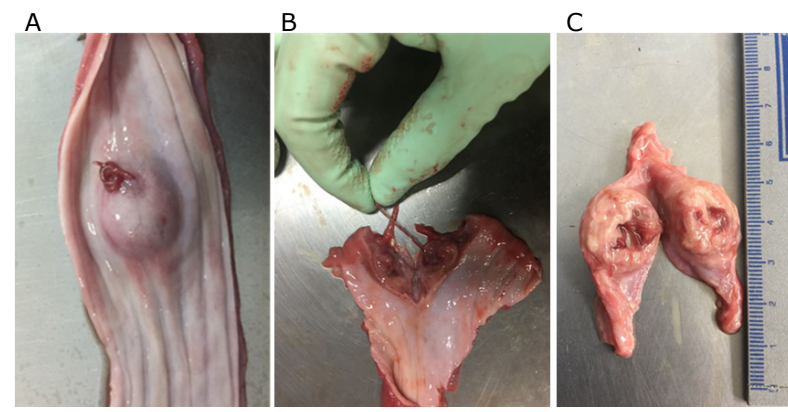

Figura 2. Nódulo en el esófago de un paciente canino (A: nódulo con una pequeña incisión y emanación de nematodos. B: extracción de nematodos C: disección del nódulo y presencia de nematodos).

De los tres nódulos se recuperaron 12 nematodos adultos de color rojo brillante de los cuales 7 fueron machos y 5 hembras (Figura 3). Los nematodos fueron clasificados como S. lupi (Figura 3) donde los machos midieron 4.2. $\pm 0.7 \mathrm{~cm}$ de longitud por $1.0 \pm 0.2 \mathrm{~mm}$ de ancho $\mathrm{y}$ las hembras $7.0 \pm 0.3 \mathrm{~cm}$ de longitud por $1.5 \pm 0.2 \mathrm{~mm}$ de ancho. La parte terminal del macho se presentó en forma espiral con ala lateral y papila, así como espiráculos desiguales. En la hembra la vulva se abre cerca de la parte final del esófago y el útero contiene huevos con cubierta gruesa.

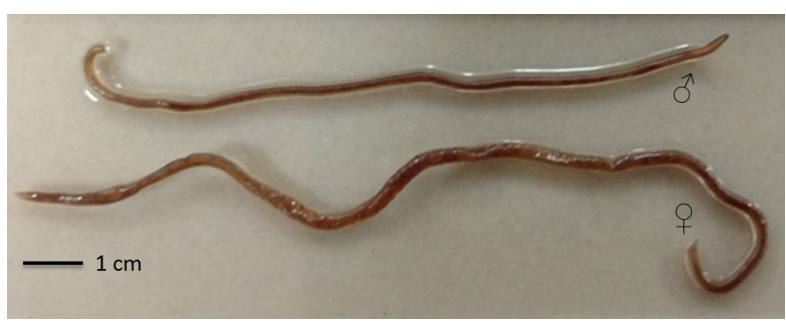

Figura 3. Macho y hembra de Spirocerca lupi obtenido de un nódulo del esófago de un perros durante la necropsia.

En el estudio coprológico de flotación centrifugada del último caso del laboratorio de parasitología se observaron huevos de $S$. lupi con una cubierta ancha y con la presencia de una larva con dimensiones de $32 \pm 1.8 \mu$ de longitud x 12.2 $\pm 1.6 \mu$ de ancho (Figura 4).

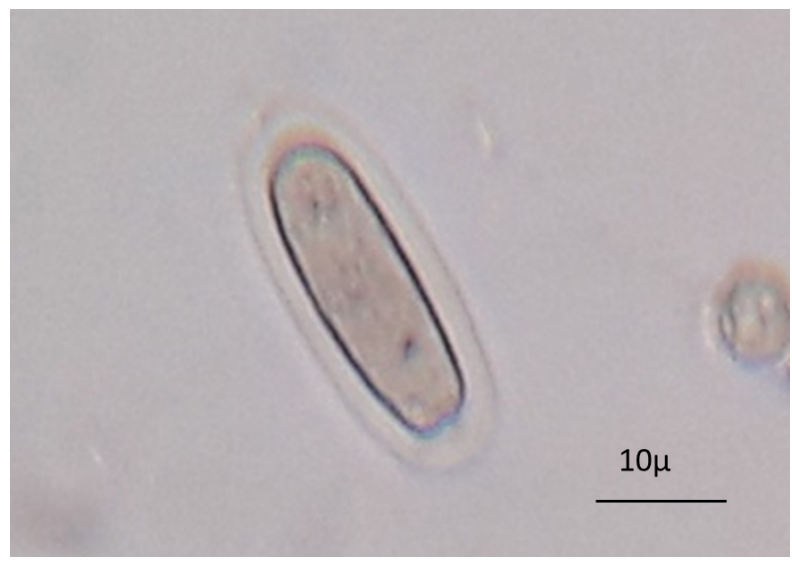

Figura 4. Huevo de Spirocerca lupi obtenido de heces de un canino en la prueba de flotación centrifugada.

Se revisaron secciones de tejido identificadas como nódulo de esófago, en donde se observó un granuloma eosinofílico, caracterizado porque en su centró se encontró una estructura parasitaria consistente con un nematodo, rodeado por un infiltrado inflamatorio severo formado por neutrófilos, eosinófilos, linfocitos, células plasmáticas y macrófagos; los cuales se encuentran delimitados por una cápsula de tejido conectivo fibroso formada por gran cantidad de fibroblastos, fibrocitos y fibras de colágena (Figura 5).

En los archivos de los laboratorios de Parasitología Veterinaria del CCBA-UADY se realizaron 1631 análisis coprológicos de muestras de heces de perros mediante las técnicas de Flotación Centrifugada y McMaster. Se encontraron tres casos de S. Iupi, por lo que presenta una prevalencia en heces de $0.18 \%$. Asimismo, en el laboratorio de Patología Animal del CCBA-UADY se revisaron los archivos y se realizaron de 2000 a 2017, 
835 necropsias de caninos encontrándose en cuatro perros con nódulos en el esófago que contenían en su interior nematodos adultos de S. lupi, lo que corresponde a una prevalencia de $0.48 \%$. Todos los perros positivos reportados en ambos laboratorios provenían del estado de Yucatán, sin antecedentes de salir del estado.

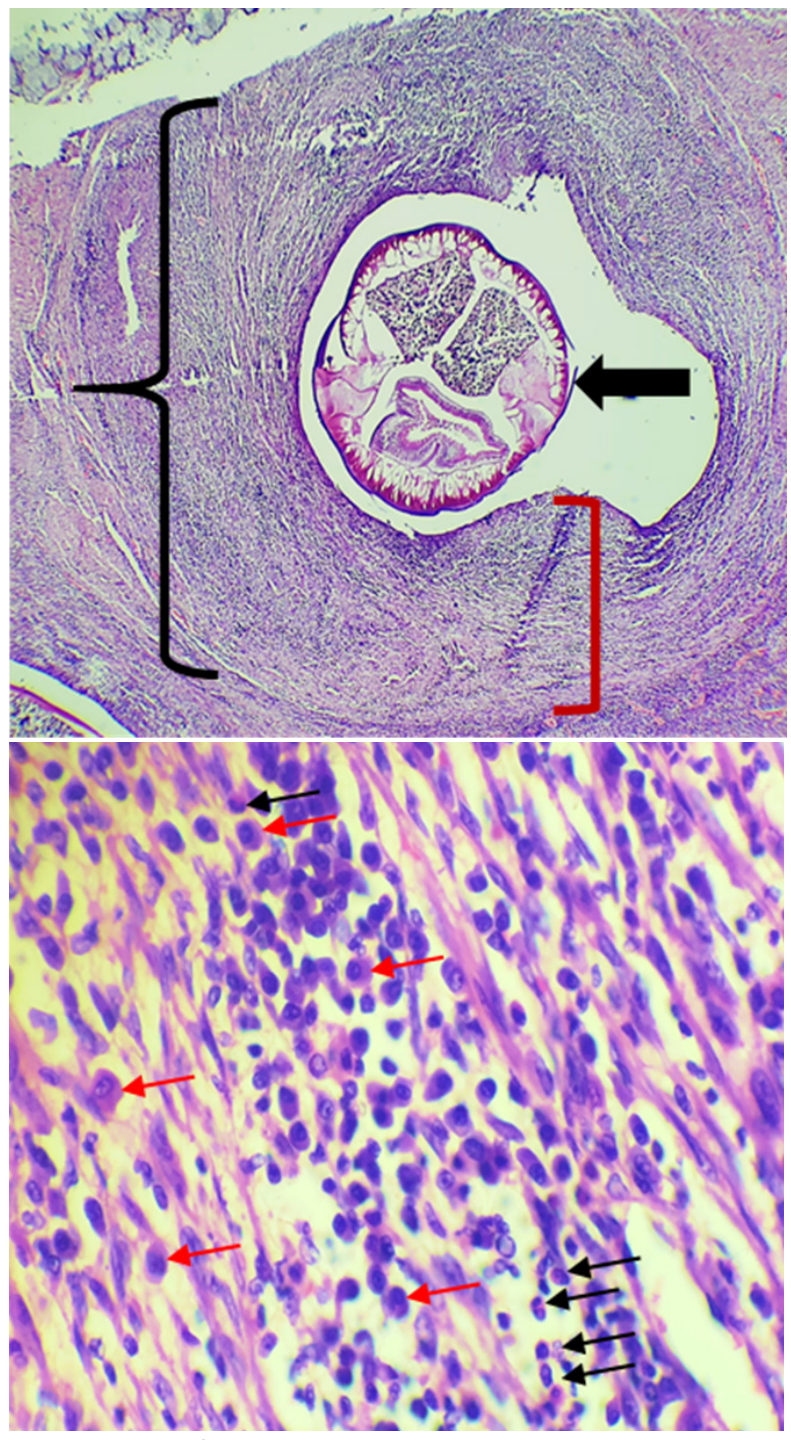

Figura 5. Tinción con hematoxilina y eosina. A. (4x) Granuloma eosinofílico (llave negra), donde se observa un nematodo central (flecha gruesa), rodeado por infiltrado inflamatorio moderada y delimitado por una capsula de tejido conectivo fibroso (corchete rojo). B. (40x) Aumento de $\mathbf{A}$, en donde el infiltrado inflamatorio está formado por eosinófilos (flecha negra), linfocitos y macrófagos (flecha roja).

En el tabla 1 se presenta los casos de perros diagnosticado con S. Iupi en los laboratorios de Parasitología y Patología Veterinaria del CCBA-UADY de 2000 al 2017.
Tabla 1. Casos de perros diagnosticados con Spirocerca lupi en perros de Yucatán, México mediante pruebas coprológicas y de necropsia.

\begin{tabular}{ccccc}
\hline Forma de Diagnóstico & $\begin{array}{c}\text { Edad del Raza del } \\
\text { perro }\end{array}$ & perro & NNE* & NHG** \\
\hline $\begin{array}{c}\text { Descripción de caso } \\
\text { Necropsia descrita en este } \\
\text { estudio (octubre 2017) }\end{array}$ & 12 años & Mestizo & 12 & NA \\
$\quad$ Retrospectivo & & & & \\
Coprológico (2002) & 5 años & Maltes & NA & 200 \\
Coprológico (2017) & 4 años & Mestizo & NA & 150 \\
Necropsia (mayo 2000) & 5 años & Mestizo & 9 & NA \\
Necropsia (febrero 2014) & 7 años & Mestizo & 7 & NA \\
Necropsia (octubre 2017) & 9 años & Mestizo & 8 & NA \\
\hline
\end{tabular}

NNE = No. de nematodos en esófago; NHG = No. huevos por gramo de heces; * Diagnosticados por necropsia, ** Diagnosticado por la prueba de McMaster, NA: No aplica

\section{DISCUSIÓN}

La Spirocercosis presenta una distribución mundial pero es predominante en regiones tropicales y subtropicales (6). La infección depende de la densidad de la población canina y del grado de contacto entre el perro y los hospederos paraténicos e intermediarios (principalmente escarabajos coprófagos). La prevalencia de esta parasitosis es muy variable y la mayoría de los casos se reportan en el sureste de EUA, Brasil, Sudáfrica, Kenia y medio oriente $(\underline{6}, \underline{16}, \underline{17})$.

Estudios de necropsia para el diagnóstico de S. Iupi en perros se han realizado en diferentes partes del mundo, con prevalencias en Sudáfrica de 14\% (16, 18), Bangladesh $40.0 \%$ (19) y España $14.2 \%$ (므).

En el presente estudio se encontraron bajas prevalencias de 0.18 y $0.48 \%$ diagnosticadas en pruebas coprológicas y necropsias, respectivamente. Estas prevalencias de $S$. lupi en perros también son bajas en comparación con estudios previos realizado en Yucatán y Querétaro, donde se encontraron prevalencias de $4.5 \%(\underline{9})$ y $5.3 \%(\underline{10})$, respectivamente. Esta tendencia a disminuir los casos de $S$. Iupi en perros de Yucatán probablemente se asocie al uso constante de antihelmínticos y en especial de lactonas macrocíclicas en perros (21) , que han demostrado ser eficaces para el control de este nematodo $(\underline{6}, \underline{22})$.

La spirocercosis se presenta principalmente en perros de áreas rurales o que estén expuestos a hospederos paraténicos. En Grecia se demostró que los perros con dueño presentaron menor prevalencia (10\%) de S. Iupi al ser comparados con perros que se usan para la cacería $(21 \%)(\underline{23})$. En el presente estudio no se pudo investigar la procedencia de los perros; sin embargo, la mayoría de los perros positivos fueron de raza mestizo que fueron adoptados por sus dueños y se podría pensar que tuvieron mayor exposición a los hospederos intermediarios y paraténicos porque parte de su vida deambularon por las calles en busca de alimento. En Yucatán, México se han reportado diferentes especies de escarabajos coprófagos y la especie Canthon leechi tiene preferencia por heces de perros (24). En futuros estudios será necesario estudiar el papel que juegan los escarabajos coprófagos dentro del ciclo de transmisión de S. lupi. 
Diferentes estudios indican que la edad de los perros no es un factor asociado a la infección con S. lupi ( $\underline{6})$. Sin embargo, en este estudio los perros positivos a S. Iupi fueron animales adultos o geriátricos con edades de 4 a 12 años.

Los perros se infectan a través de la ingestión de las larvas $L_{3}$ de $S$. Iupi. Esto ocurre mediante el consumo directo de escarabajos coprófagos o por el consumo de alimentos contaminados; los roedores, aves, conejos y lagartijas como hospederos paraténicos son otra ruta de transmisión potencial. Las larvas penetran la pared del estómago de los perros y migran a la aorta torácica vía las arterias gástricas. Las larvas mudan a $\mathrm{L}_{4}$ y adultos inmaduros. En 3-4 meses migran al esófago donde madura y son rodeados por nódulos granulomatosos que se forman alrededor del parásito como parte de la respuesta inflamatoria del perro $(\underline{5}, \underline{6})$.

Durante la necropsia del perro se observaron tres nódulos en el esófago que durante la incisión de la masa permitió visualizar nematodos adultos de S. Iupi. En el estudio histológico se observó en los nódulos con granuloma eosinofílico, con presencia del nematodo rodeado por un infiltrado inflamatorio severo por neutrófilos, eosinófilos, linfocitos, células plasmáticas y macrófagos. Estos hallazgos coinciden con lo reportado por Diakou et al (25) quienes describen que los granulomas consisten en un área central que se encuentran rodeado de eosonófilos degenerados y viables, así como la infiltración de neutrófilos como parte de la respuesta inmune del animal. Asimismo, estos se encuentran delimitados por tejido conectivo infiltrado predominantemente por células mononucleares, específicamente histiocitos, células plasmáticas y linfocitos.

La patogénesis de $S$. lupi para inducir neoplasias no ha sido bien elucidada $(\underline{26}, \underline{27})$. Se sugiere que los sarcomas esofagiales sean producidos por las larvas de S. lupi ( $\underline{3})$. Se cree que los parásitos interfieren con los procesos celulares de relevancia en la carcinogénesis, actuando en la comunicación intercelular o mediante la secreción de moléculas con potencial carcinógeno (28). Pueden producirse fibrosarcomas y osteosarcoma con la posibilidad de ocurrir metástasis en los pulmones $(\underline{3})$, patología que no ocurrió en el caso descrito en este estudio. El desarrollo de estos tumores conduce a obstrucciones esofágicas y disnea, lo que puede conducir a un cuadro clínico severo que puede ocasionar la muerte de los perros.

Se concluye que S. Iupi se encuentra presente en perros de Yucatán, México con prevalencias bajas, produciendo en el esófago de los perros lesiones caracterizadas por granulomas eosinofílicos. Se pone de manifiesto necesidad de incluir esta patología en el diagnóstico diferencial de problemas esofágicos y respiratorios en perros.

\section{Conflicto de interés.}

Los autores declaramos no tener conflicto de intereses de ninguna índole.

\section{REFERENCIAS}

1. Psáder R, Balogh M, Pápa K, Sterczer A, Lukács Z, Harnos A. Occurrence of Spirocerca lupi infection in hungarian dogs referred for gastroscopy. Parasitol Res. 2017; 116:S99-S108. https://doi. org/10.1007/s00436-017-5496-9

2. Lobetti R. Spirocercosis. Canine and feline gastroenterology. Washabau RJ, Day MJ (ed). Elsevier Saunders; St. Luis: 2013.

3. Ranen E, Lavy E, Aizenberg I, Perl A., Harrus S. Spirocercosis - associated esophageal sarcomas in dogs. A retrospective study of 17 cases (19972003). Vet Parasitol. 2004; 119(2-3):209-221. https://doi.org/10.1016/j.vetpar.2003.10.023

4. Christie J, Schwan EV, Bodenstein LL, Sommerville JE, Van der Merwe LL. The sensitivity of direct faecal examination, direct faecal flotation, modified centrifugal faecal flotation and centrifugal sedimentation/flotation in the diagnosis of canine spirocercosis. J S Afr Vet Assoc. 2011; 82:71-75.

5. Wright I. Spirocerca lupi - a potential future problem for pets travelling to Europe. Companion Anim. 2015; 20(3):156-160. https://doi.org/10.12968/ coan.2015.20.3.156
6. van der Merwe LL, Kirbergera RM, Clift S, Williams $\mathrm{M}$, Keller N, Naidoo V. Spirocerca lupi infection in the dog: A review. Vet J. 2008; 176:294-309. https:// doi.org/10.1016/j.tvjl.2007.02.032

7. Giannelli L, Baldassarre V, Ramos RAN, Lia RP, Furlanello T, Trotta M et al. Spirocerca lupi infection in a dog from southern Italy: an old fashioned disease? Parasitol Res. 2014; 113:2391. https:// doi.org/10.1007/s00436-014-3912-y

8. Elias $F$, Barros RM, Santos-Junior HL, Eloi RSA, Silva V, Freitas F, Fonseca-Alves CE. Pathological alterations in dogs resulting from parasitism by Spirocerca lupi. Acta Sci Vet. 2016; 44(Suppl 1):145. http://revistas.bvs-vet.org.br/actascivet/ article/view/31571/34927

9. Cantó GJ, García MP, García A, Guerrero MJ, Mosqueda $\mathrm{J}$. The prevalence and abundance of helminth parasites in stray dogs from the city of Queretaro in central Mexico. J Helminthol. 2011; 85:263-269. https://doi.org/10.1017/ $\underline{\mathrm{s} 0022149 \times 10000544}$ 
10. Quiñones-Avila F, Espaine AL, Rodríguez-Vivas RI, Domínguez-Alpizar J. Contribución al estudio de los helmintos del tracto digestivo en perros de la ciudad de Mérida, Yucatán, México. Rev AMMVEPE 1998; 9(6):191-193.

11. INEGI (Instituto Nacional de Estadística, Geografía e Información) [Base de datos de internet]. Anuario estadístico y geográfico de Yucatán México. 2017 [actualizado el 28 de abril de 2018]. URL Disponible en: http://www.datatur.sectur.gob.mx/ ITXEF_DOCS/YUC ANUARIO PDF.pdf

12. Rodríguez-Vivas RI editor. Técnicas para el diagnóstico de parásitos con importancia en salud pública y veterinaria. AMPAVE-CONASA; México DF: 2015.

13. Bowman DD, Lynn RC, Eberhard ML. Georgi's parasitology for veterinarians. 8th edn. St. Louis, Missouri; Saunders: 2003.

14. Mescher AL. Junqueira's Basic Histology: Text and Atlas. 14th Edition. Ed. McGraw-Hill Education; New York, USA: 2016.

15. Schueneman de AA, Constantino CF. Técnicas de necropsia en animales domésticos. 2a edición. Manual Moderno; México, D.F: 2002.

16. Minnaar WN, Krecek RC. Helminths in dogs belonging to people in a resource-limited urban community in Gauteng, South Africa. J Vet Res. 2001; 68:111-117. PMID: 11585088

17. Dantas-Torres F, Otranto D. Dogs, cats, parasites, and humans in Brazil: opening the black box. Parasit Vectors. 2014; 7:22. https://doi.org/10.1186/17563305-7-22

18. Lobetti R. Follow-up survey of the prevalence, diagnosis, clinical manifestations and treatment of Spirocerca lupi in South Africa. J S Afr Vet Assoc. 2014; 85(1):7. https://doi.org/10.4102/jsava. $\underline{\mathrm{v} 85 \mathrm{i} 1.1169}$

19. Shubhagata $D$, Abdul A, Mohammad MH, Suchandan S, Muraduzzaman M. Spirocercosis in stray dogs of Chittagong Metropolitan area of Bangladesh: an epidemiological and pathological investigation. Vet World. 2011; 4:485-491. https://doi.org/10.5455/ vetworld.2011.485-491

20. Chikweto A, Bhaiyat MI, Tiwari KP, de Allie C, Sharma RN. Spirocercosis in owned and stray dogs in Grenada. Vet Parasitol. 190; 2012:613-616. https://doi.org/10.1016/j.vetpar.2012.07.006
21. Rodriguez-Vivas RI, Ojeda-Chi MM, TrinidadMartinez I, Pérez de León AA. First documentation of ivermectin resistance in Rhipicephalus sanguineus sensu lato (Acari: Ixodidae). Vet Parasitol. 2017; 233:9-13. https://doi.org/10.1016/j. vetpar.2016.11.015

22. Austin CM, Kok DJ, Crafford D, Schaper R. The efficacy of a topically applied imidacloprid 10 \%/moxidectin $2.5 \%$ formulation (Advocate $®$, Advantage $\AA$ Multi, Bayer) against immature and adult Spirocerca lupi worms in experimentally infected dogs. Parasitol Res. 2013; 112:91-108. https://doi.org/10.1007/s00436-013-3284-8

23. Mylonakis ME, Koutinas AF, Liapi MV, Saridomichelakis MN, Rallis TS. A comparison of the prevalence of Spirocerca lupi in three groups of dogs with different life and hunting styles. J Helminthol. 2001; 75:359361. PMID: 11818054

24. Rodríguez-Vivas RI, Basto-Estrella G, ReyesNovelo E, Delfín-González H, Pérez-Cogollo LC, Ojeda-Chi $\mathrm{M}$ et al. Escarabajos estercoleros en Yucatán, México: Especies, distribución estacional e incorporación de excretas al suelo. Rev Nuestro Agro. 2014; 1:18-24.

25. Diakou A, Karamanavi E, Eberhard M, Kaldrimidou E. First report of Spirocerca lupi infection in red fox Vulpes vulpes in Greece. Wildl Biol. 2012; 18(3):333-336. https://doi.org/10.2981/11-094

26. Mukorera V, van der Merwe LL, Lavy E, Aroch I, Dvir E. Serum alkaline phosphatase activity is not a marker for neoplastic transformation of esophageal nodules in canine spirocercosis. Vet Clin Pathol. 2011; 40(3):389-392. https://doi.org/10.1111/ j.1939-165X.2011.00331.X

27. Klainbart S, Mazaki-Tovi M, Auerbach N, Aizenberg I, Bruchim Y, Dank G. Spirocercosis - associated pyothorax in dogs. Vet J. 2007; 173(1):209-214. https://doi.org/10.1016/j.tvjl.2005.08.019

28. Santos ASO, Silveira LS, Lemos LS, Moreira L, Silva AC, Carvalho ECQ. Aneurismas aórticos pela espirocercose canina em Brasília (Relato de caso). Rev Bras Saúde Prod Anim. 2004; 5(1):25-30. http://revistas.ufba.br/index.php/rbspa/article/ view/628/385 